\title{
Multivariate optimization of a method for antimony determination by hydride generation atomic fluorescence spectrometry in hair samples of patients undergoing chemotherapy against Leishmaniasis
}

\author{
MANUELLE C. CARDOZO ${ }^{1}$, DANNUZA D. CAVALCANTE ${ }^{2,3}$, \\ DANIEL L.F. SILVA ${ }^{2}$, WALTER N.L. DOS SANTOS ${ }^{2,3}$ and MARCOS A. BEZERRA ${ }^{1}$ \\ ${ }^{1}$ Departamento de Química e Exatas, Universidade Estadual do Sudoeste da Bahia, \\ Rua José Moreira Sobrinho, s/n, 45206-191 Jequié, BA, Brasil \\ ${ }^{2}$ Departamento de Ciências Exatas e da Terra, Universidade do Estado da Bahia, \\ Rua Silveira Martins, 2555, 40170-290 Salvador, BA, Brasil \\ ${ }^{3}$ Departamento de Química Analítica, Universidade Federal da Bahia, Instituto de \\ Química, Rua Barão de Jeremoabo, 147, 40170-115 Salvador, BA, Brasil
}

Manuscript received on April 3, 2015; accepted for publication on September 3, 2015

\begin{abstract}
A method was developed for determination of total antimony in hair samples from patients undergoing chemotherapy against Leishmaniasis based on the administration of pentavalent antimonial drugs. The method is based on microwave assisted digestion of the samples in a pressurized system, reduction of $\mathrm{Sb}^{5+}$ to $\mathrm{Sb}^{3+}$ with KI solution $(10 \% \mathrm{w} / \mathrm{v})$ in ascorbic acid $(2 \%, \mathrm{w} / \mathrm{v})$ and its subsequent determination by hydride generation atomic fluorescence spectrometry (HG-AFS). The proportions of each component $\left(\mathrm{HCl}, \mathrm{HNO}_{3}\right.$ and water) used in the digestion were studied applying a constrained mixtures design. The optimal proportions found were $50 \%$ water, $25 \% \mathrm{HNO}_{3}$ and $25 \% \mathrm{HCl}$. Variables involved in the generation of antimony hydride were optimized using a Doehlert design revealing that good sensitivity is found when using $2.0 \% \mathrm{w} / \mathrm{v} \mathrm{NaBH}_{4}$ and $4.4 \mathrm{~mol} \mathrm{~L}^{-1} \mathrm{HCl}$. Under the optimum experimental conditions, the method allows the determination of antimony in hair samples with detection and quantification limits of 1.4 and $4.6 \mathrm{ng} \mathrm{g}^{-1}$, respectively, and precision expressed as relative standard deviation (RSD) of $2.8 \%$ ( $\mathrm{n}=10$ to $10.0 \mathrm{mg} \mathrm{L}^{-1}$ ). The developed method was applied in the analysis of hair samples from patients who take medication against Leishmaniasis.
\end{abstract}

Key words: Leishmaniasis, antimony, hair, HG-AFS, multivariate optimization.

\section{INTRODUCTION}

Leishmaniasis is an infectious disease caused by parasites of the genus Leishmania, which can infect humans in the cutaneous and visceral (or kala-

Correspondence to: Marcos de Almeida Bezerra

E-mail: mbezerra@uesb.edu.br azar) forms. It constitutes a public health problem considered by the World Health Organization (WHO) as one of the six most important infectious diseases that require greater attention by governments (Brasil 2007). The use of pentavalent antimony (such as $\mathrm{N}$-methylglucamine antimoniate and sodium stibogluconate) for its treatment had its 
standardization determined by the WHO. Despite being among the agents considered toxic to human health and the potential severity of their features, antimonials are the first choice drugs for the treatment of Leishmaniasis. The amounts given are calculated as $\mathrm{mg}$ of $\mathrm{Sb}^{5+} \mathrm{kg}^{-1} \mathrm{day}^{-1}$, so that the maximum permitted daily dose for adults is equivalent to 1215 $\mathrm{mg} \mathrm{Sb}^{5+}$ day $^{-1}$. Their effects lead to question the harm arising from their accumulation in the human body, since they have proved to be a toxic agent (Brasil 2007, Fouce et al. 1998).

Among the several biological matrices used for the study of metal accumulation in the human body the capillary tissue stands out. Its analysis has been widely used as a tool for assessing risk exposures. The advantage of using this matrix can be noted for its ability to monitor elements accumulated over a period of time as well as its simplicity in relation to sampling, shipping, and handling (Violante et al. 2000, Forte et al. 2005).

Nowadays, different analytical methods are available for the measuring of antimony in several samples. The most often-used sensitive analytical techniques for this purpose are hydride generation coupled to: atomic absorption spectrometry (HG AAS) (Krachler et al. 2001), inductively coupled plasma optical emission spectrometry (HG ICP OES) (Mihaltan et al. 2013) and atomic fluorescence spectrometry (HG-AFS) (Rahman et al. 2000). Without the need of coupling hydride generation, graphite furnace atomic absorption spectrometry (GFAAS) (Mendil et al. 2013) and inductively coupled plasma mass spectrometry (ICP MS) (Chevallier et al. 2015) can be used. However, coupling hydride generation to these two techniques improves their analytical characteristics. On the other hand, even though ICP and GFAAS techniques have good sensitivity, they present a high instrumental cost (Sezgin et al. 2015). HGAFS is a relatively low-cost and highly sensitivity technique for this task, allowing also good accuracy, precision, speed and reliability in the analysis.
Atomic fluorescence spectrometry (AFS) is a technique that is based on the excitation of atoms in the gaseous phase and from the ground state using characteristic radiation photons of the element of interest and in the measurement of fluorescence radiation emitted at an angle of 90 degrees (Hage and Carr 2012). The coupling of hydride generation (HG) with AFS allows the determination of elements such as $\mathrm{As}, \mathrm{Sb}, \mathrm{Se}, \mathrm{Te}, \mathrm{Bi}, \mathrm{Hg}$, among others, with very low detection limits, good precision, accuracy and confidence (Santos et al. 2013). HG-AFS has become a viable alternative for the quantification of hydride-forming elements due to their excellent performance in the determination of trace and the low cost compared to other spectrometric techniques. This technique has been used in several studies aimed at determination of $\mathrm{Sb}$ and other elements, among which are highlighted: $\mathrm{Se}^{4+}$ and $\mathrm{Se}^{6+}$ in natural water samples after preconcentration using $\mathrm{TiO}_{2}$ nanoparticles ( $\mathrm{Fu}$ et al. 2012), Se determination in plants and peat samples (García et al. 2005), Sb speciation in algae samples and marine mollusks after organic species separation by HPLC coupled to HG-AFS (Gregori et al. 2007), $\mathrm{As}^{3+}$ and $\mathrm{As}^{5+}$ determination from soils using sequential extraction carried out by a flow injection system coupled to HG-AFS (Shi et al. 2003), $\mathrm{As}^{3+}$ and $\mathrm{As}^{5+}$ speciation from vegetables after ultrasound assisted extraction (Reyes et al. 2008), speciation of inorganic As in edible mushrooms (Gonzálvez et al. 2009), Se determination from food commercialized in Slovenia (Smrkolj et al. 2005), determination of $\mathrm{As}, \mathrm{Sb}, \mathrm{Se}, \mathrm{Te}$ and $\mathrm{Bi}$ in vegetables and cereals consumed by a Spanish population (Matos-Reyesa et al. 2010), determination of $\mathrm{Sb}$, As and $\mathrm{Hg}$ in aquatic amphibians and earthworms collected in the vicinity of a mine for antimony exploration in China (Fu et al. 2011), determination of As, Sb, Se, $\mathrm{Te}$ and $\mathrm{Bi}$ in milk by using a sampling technique for suspension (Montesinos et al. 2004), determining the degree of leaching and speciation of $\mathrm{Sb}$ in coal ashes (Miravet et al. 2006), simultaneous speciation 
of As and $\mathrm{Sb}$ after preconcentration using carbon nanotubes as a solid phase and an AFS dual-channel spectrometer (Wu et al. 2011).

Optical methods based on hydride generation used for antimony determination from hair samples demand a digestion procedure. Traditionally, this digestion is carried out using $\mathrm{HNO}_{3} / \mathrm{H}_{2} \mathrm{O}_{2}$ in open system (such as hot plate) to eliminate the exceeding of oxidant which affects the formation of metallic hydride (Liu et al. 2011). Digestion in closed systems using Teflon bomb and microwave irradiation presents several advantages such as: avoidance of the loss of volatile elements and contamination and presenting speed in the digestion (Ferreira et al. 2014). Due to all this advantages, in this work, studies were conducted with the objective to develop an analytical method using microwave digestion in a closed system and HGAFS technique for the quantification of antimony in hair samples from patients undergoing therapy with antimonial drugs.

\section{MATERIALS AND METHODS}

\section{INSTRUMENTATION}

To measure the fluorescence intensity of the antimony, an atomic fluorescence spectrometer with hydrides generator, HG-AFS (Model 3300 Lumina, Aurora Biomedic Inc, Canada) was used with a coupled quartz gas-liquid separator. Argon (White Martins) was used as carrier gas and the flame was maintained by the $\mathrm{H}_{2}$ generated parallel to the hydride reaction of $\mathrm{HCl}$ with $\mathrm{NaBH}_{4}$. A high intensity hollow cathode lamp (Aurora, Aurora Biomedic Inc, Canada) was used as excitation source of the analyte. The experimental conditions of the spectrometer operation are given in Table I.

Microwave energy assisted digestion of hair samples was performed in a digestion system constituted by $23 \mathrm{~mL}$ of polytetrafluoroethylene (Teflon) cups coupled to a casing constructed with
TABLE I

Operational parameters of HG-AFS for antimony determination.

\begin{tabular}{|c|c|}
\hline Parameter & Value \\
\hline Primary current of lamp (mA) & 100 \\
\hline Atomizer observation height (mm) & 8 \\
\hline Argon pressure (psi) & 30 \\
\hline Carrier gas flow rate $\left(\mathrm{mL} \mathrm{min}^{-1}\right)$ & 400 \\
\hline Auxiliar gas flow rate $\left(\mathrm{mL} \mathrm{min}{ }^{-1}\right)$ & 800 \\
\hline DBD applied power (W) & 12 \\
\hline $\mathrm{NaBH}_{4}$ flow rate $\left(\mathrm{mL} \mathrm{min}{ }^{-1}\right)$ & 1.4 \\
\hline Sampling flow rate $\left(\mathrm{mL} \mathrm{min}^{-1}\right)$ & 4.0 \\
\hline Excitation and emission wavelength (nm) & 217.6 \\
\hline
\end{tabular}

polymeric material (4749 Parr, Moline, IL, USA) suitable for penetration by the microwaves.

A Liotop lyophilizer (Model K202, São Carlos, Brazil) was used to remove humidity from the samples making them more brittle for efficient comminuting. The samples were comminuted using a ball mill tungsten carbide $8000 \mathrm{M}$ (Spex Sample Prep, USA). A purification system Purelab Classic (Elga, High Wycombe, UK) was used for generation of ultra-pure water with resistivity of $18.2 \mathrm{MW} \mathrm{cm}^{-1}$. A Sartorius analytical balance ED124S model (Gottingen, Germany) was used to obtain mass of samples and reagents.

\section{REAGENTS AND SOLUTION}

All solutions were prepared using ultrapure water. Nitric and hydrochloric acids (Merck, Darmstadt, Germany) used were of analytical grade. The antimony standard solutions were obtained by diluting a Titrisol stock solution $1000 \mathrm{mg} \mathrm{L}^{-1}$ (Merck Darmstadt, Germany). Working solutions were prepared by appropriate dilution of a middle solution of $10 \mathrm{mg} \mathrm{L}^{-1}$.

The reducing agent was $2.2 \%(\mathrm{w} / \mathrm{v})$ sodium tetrahydroborate, stabilized with $0.5 \%(\mathrm{w} / \mathrm{v})$ sodium hydroxide. This solution was daily prepared using analytical grade chemicals (Merck, Darmstadt, Germany) and filtered through a 0.45 
$\mu \mathrm{m}$ cellulose membrane. A solution of $10 \%(\mathrm{w} / \mathrm{v})$ potassium iodide and $2 \%(\mathrm{~m} / \mathrm{v})$ ascorbic acid was prepared by dilution of reagents in ultrapure water.

Each polyethylene container used was rinsed with deionized water and an Extran solution, decontaminated with a solution of nitric acid $10 \%$ (v/v) for 12 hours and rinsed three times with ultrapure water and dried in dust-free environment prior to use.

\section{COLLECTION AND SAMPLE PRE-TREATMENT}

Ten hair samples of patients who underwent drug treatment against Leishmaniasis, and three hair samples from donors not undergoing treatment were collected. The samples were collected in the region just above the neck. This collection site is recommended because it is less susceptible to external contamination, also because there is almost always hair on bald men in this region. About 0.5 $\mathrm{g}$ of hair was collected. For this purposes gloves and stainless steel scissors were used, being very careful not to change the aesthetics of the donor's hair through the spacing of the removed hair. After collection, the hair samples were stored in plastic bags, and kept in a clean and dry place. Afterwards, the hair was rinsed to remove dust, sweat, grease, etc, for analysis. The samples were individually immersed in a $5 \%(\mathrm{v} / \mathrm{v})$ Triton X-100 solution with manual shaking for $5 \mathrm{~min}$ and rinsed three times with deionized water. Subsequently, they were dried at room temperature between sheets of filter paper. After drying, the samples were freeze-dried, ground in tungsten carbide ball mills and stored in polyethylene containers previously decontaminated with a solution of $10 \% \mathrm{HNO}_{3}$ (Borella et al. 1996).

\section{$\mathrm{SBH}_{3}$ GENERATION OPTIMIZATION}

The optimization of the variables involved in the stibnite $\left(\mathrm{SbH}_{3}\right)$ generation were performed by applying a Doehlert design (Table II). The variables studied were the $\mathrm{HCl}$ solution concentrations
TABLE II

Doehlert design applied to optimization of stibnite generation.

\begin{tabular}{cccc}
\hline $\begin{array}{c}\text { Experi- } \\
\text { ment }\end{array}$ & $\begin{array}{c}\mathbf{H C l} \\
\left(\mathbf{m o l ~ L}^{-1}\right)\end{array}$ & $\begin{array}{c}\mathbf{N a B H}_{4} \\
(\% \mathbf{m} / \mathbf{v})\end{array}$ & $\begin{array}{c}\text { Sb } \\
\text { fluorescence } \\
\text { intensity }\end{array}$ \\
\hline 1 & $6.0(1.0)$ & $2.0(0)$ & $356.1 / 381.2$ \\
\hline 2 & $5.0(0.5)$ & $1.5(-0.866)$ & $246.4 / 282.0$ \\
\hline 3 & $5.0(0.5)$ & $2.5(0.866)$ & $397.4 / 366.4$ \\
\hline 4 & $4.0(0)$ & $2.0(0)$ & $303.2 / 332.7$ \\
\hline 5 & $3.0(-0.5)$ & $1.5(-0.866)$ & $204.0 / 204.7$ \\
\hline 6 & $3.0(-0.5)$ & $2.5(0.866)$ & $357.7 / 332.2$ \\
\hline 7 & $2.0(-1.0)$ & $2.0(0)$ & $175.2 / 160.6$ \\
\hline
\end{tabular}

Values inside parenthesis are codified coordinates of experimental points.

added to the digested sample and the $\mathrm{NaBH}_{4}$ solution concentration used for hydride generation. The experiments were performed in random order and in duplicate to obtain the experimental error. The evaluated responses were the fluorescence intensities of antimony obtained in each experiment. Data were treated using the software Statistica ${ }^{\circledR}$ for Windows.

\section{OPTIMIZATION OF HAIR SAMPLE DIGESTION}

The proportions of the digester mixture comprising $\mathrm{HNO}_{3}, \mathrm{HCl}$ and water used for digesting about 0.1 $\mathrm{g}$ of the sample were optimized using constrained mixture design (Bezerra et al. 2010) as shown in Table III. The final volume of the mixture was always $4.0 \mathrm{~mL}$. The settings of restrictions on the reagents' proportions were necessary to avoid experimental regions of low efficiency of digestion. The microwave digestion was performed in pressurized vessels according to the following schedule: three heater stages of 1 minute with 1 minute pause between them using power of $350 \mathrm{~W}$. Figure 1 shows the experimental region bounded by the established restrictions. The response 
TABLE III

Constraints for the mixture components and results in terms of fluorescence intensity.

\begin{tabular}{|c|c|c|c|c|}
\hline \multicolumn{5}{|c|}{ Constraints } \\
\hline & Mixture variable & & Low constraint & High constraint \\
\hline & $\mathrm{HCl}$ concentration & & 0 & $0.5(2.0)$ \\
\hline & $\mathrm{HNO}_{3}$ concentration & & 0 & $0.5(2.0)$ \\
\hline & Deionized water & & 0 & $0.5(2.0)$ \\
\hline \multicolumn{5}{|c|}{ Matrix of experimental design and responses } \\
\hline Exp & HCl & $\mathrm{HNO}_{3}$ & Water & Fluorescence Intensity \\
\hline 1 & $0(0)$ & $0.5(2.0)$ & $0.5(2.0)$ & $735 / 702$ \\
\hline 2 & $0.5(2.0)$ & $0(0)$ & $0.5(2.0)$ & $476 / 452$ \\
\hline 3 & $0.5(2.0)$ & $0.5(2.0)$ & $0(0)$ & $719 / 726$ \\
\hline 4 & $0.5(2.0)$ & $0.25(1.0)$ & $0.25(1.0)$ & $708 / 712$ \\
\hline 5 & $0.25(1.0)$ & $0.5(2.0)$ & $0.25(1.0)$ & $738 / 731$ \\
\hline 6 & $0.25(1.0)$ & $0.25(1.0)$ & $0.5(2.0)$ & $726 / 715$ \\
\hline 7 & $0.33(1.3)$ & $0.33(1.3)$ & $0.33(1.3)$ & $715 / 731$ \\
\hline
\end{tabular}

Sample mass: $0.1 \mathrm{~g}$; Final volume of reagents in the digested bomb: $4.0 \mathrm{~mL}$; Heating time: $3 \mathrm{~min}$; Final volume of digested: 10.0 $\mathrm{mL}$. Values inside parenthesis are volumes (in $\mathrm{mL}$ ) corresponding to proportions established by the design.

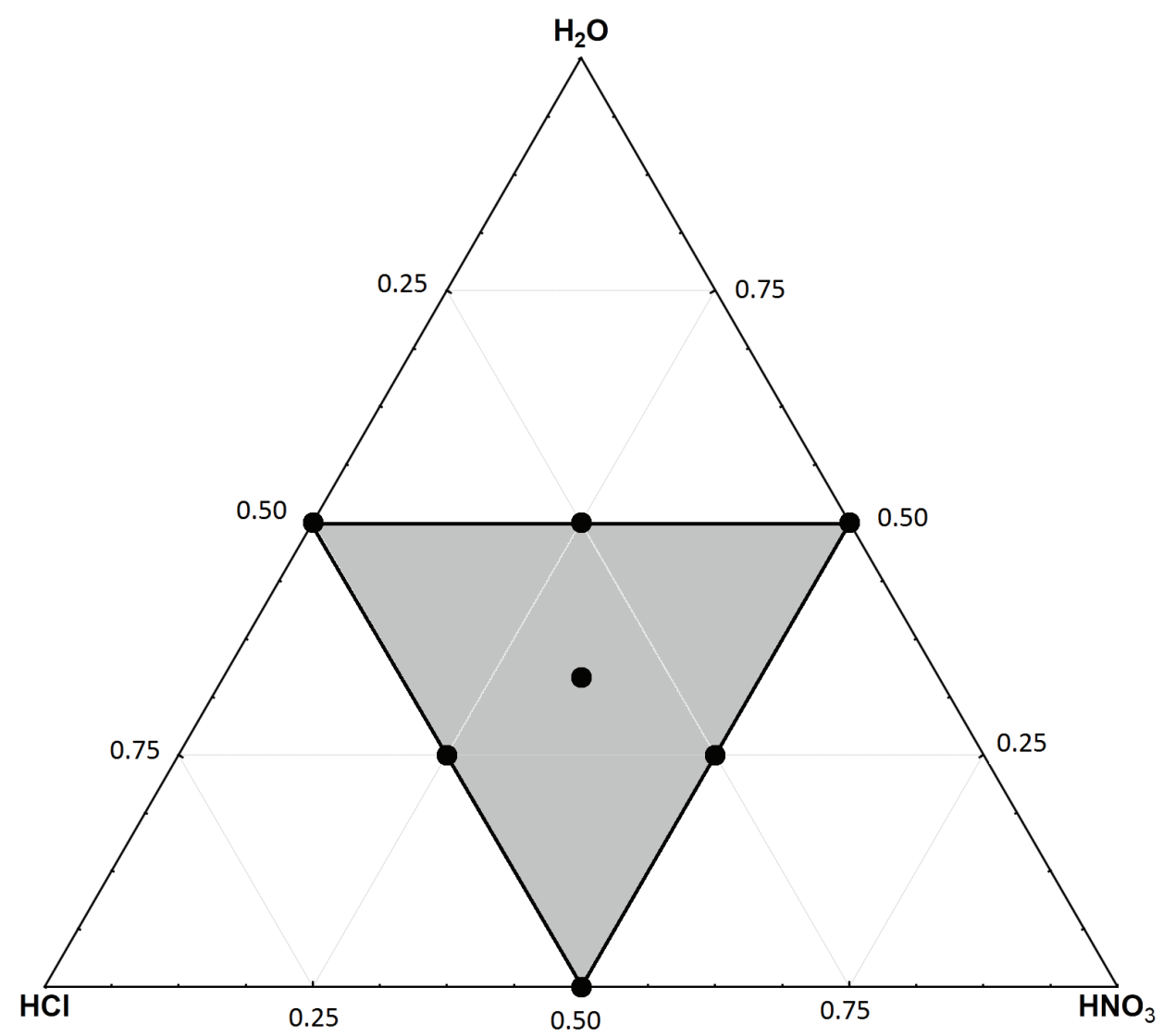

Figure 1 - Experimental region of the mixture design delimited by the high constraints established for each component according to Table II. 
measured in the optimization process was the intensity of fluorescence emission. All experiments were performed in random order. Data were treated using the software Statistica ${ }^{\circledR}$ for Windows.

GENERAL PROCEDURE AFTER OPTIMIZATION

About $0.1 \mathrm{~g}$ of each sample was weighed in a Teflon bomb and $1 \mathrm{~mL}$ of concentrated $\mathrm{HCl}, 1 \mathrm{~mL}$ of concentrated $\mathrm{HNO}_{3}$ and $2 \mathrm{~mL}$ of $\mathrm{H}_{2} \mathrm{O}$ were added to it. Subsequently, the samples were subjected to microwave assisted digestion (power $350 \mathrm{~W}$ ) for three minutes, with 1 minute intervals between irradiations. The digested samples were filtered and swelled to $10 \mathrm{~mL}$ with deionized water. Then to $0.5 \mathrm{~mL}$ of the digested samples we added $2 \mathrm{~mL}$ of $4.7 \mathrm{~mol} \mathrm{~L}^{-1} \mathrm{HCl}, 2 \mathrm{~mL}$ of $\mathrm{KI} 10 \% \mathrm{w} / \mathrm{v}$ in $2 \% \mathrm{w} / \mathrm{v}$ ascorbic acid for pre-reduction of $\mathrm{Sb}^{+5}$ and waited for 20 minutes. The obtained solution was set to $10.0 \mathrm{~mL}$ and submitted to the stibnite generation with $2.2 \% \mathrm{~m} / \mathrm{v} \mathrm{NaBH}_{4}$ and $4.7 \mathrm{~mol} \mathrm{~L}^{-1} \mathrm{HCl}$ for subsequent determination by atomic fluorescence spectrometry.

\section{ETHICAL ASPECTS OF THE RESEARCH}

The research was conducted in accordance with the provisions of Resolution No. 466/12 of the Brazilian National Health Council (Brasil 2012), which rules on standards and guidelines ruling scientific research involving human subjects and was approved by the Ethics Committee in Research of the Universidade Estadual do Sudoeste da Bahia (Registered by the code CAAE 06081112.4.0000.0055A). The suppliers of the samples were informed about the objectives of the study and ensured that the research would not cause any damage. Anonymity and confidentiality were warranted and they provided their participation by signing the consent form.

\section{RESULTS AND DISCUSSION}

\section{OPTIMIZATION OF EXPERIMENTAL CONDITIONS}

Conditions of stibine generation were optimized using a Doehlert design and the evaluated response was the intensity of the fluorescence emission from $\mathrm{Sb}$. This design and the obtained responses for each experiment are shown in Table II. The fitting of the quadratic mathematical model generated the following equation:

$$
\begin{aligned}
\mathbf{y}= & -\mathbf{5 0 3 . 7}( \pm \mathbf{2 4 2})+\mathbf{1 6 3 . 8}( \pm \mathbf{4 0 . 7}) \mathrm{C}_{\mathrm{HCl}} \\
& -\mathbf{1 2 . 4}( \pm \mathbf{3 . 9 2}) \mathrm{C}_{\mathrm{HCl}}{ }^{2}+281.8( \pm 195) \mathrm{C}_{\mathrm{BH}} \\
& -26.73( \pm 47.1) \mathrm{C}_{\mathrm{BH}}{ }^{2}-11.45( \pm 12.8) \mathrm{C}_{\mathrm{HCl}} \mathrm{C}_{\mathrm{BH}}
\end{aligned}
$$

where $\mathrm{y}$ is the response, $\mathrm{C}_{\mathrm{HCl}}$ is the acid concentration and $\mathrm{C}_{\mathrm{BH}}$ is the $\mathrm{NaBH}_{4}$ concentration. The terms in bold are statistically significant at a confidence level of $90 \%$.

The response surface (Figure 2) described by the equation presents a shape that characterizes it as maximum. The calculation of the maximum point coordinates shows that the optimum conditions are $\mathrm{C}_{\mathrm{HCl}}=4.7 \mathrm{~mol} \mathrm{~L}^{-1}$ and $\mathrm{C}_{\mathrm{BH}}=4.2 \% \mathrm{~m} / \mathrm{v}$. However, the $\mathrm{NaBH}_{4}$ is outside the studied experimental region and was obtained by extrapolation. As, in this condition, there is no considerable gain in sensitivity using this concentration in relation to the $2.0 \% \mathrm{~m} / \mathrm{v} \mathrm{NaBH}_{4}$ solution, it was decided to use this last concentration to economize the reducing reagent. Analysis of Variance (ANOVA) has shown that quadratic model does not present significant lack of fit when using a confidence level of $99 \%$ $(p$-value $=0.0129>0.01)$ and it can be used for explain the data behavior inside the studied experimental field.

Hair samples must need to undergo a process of digestion in order to be analyzed by HG-AFS. $\mathrm{As} \mathrm{Sb}$ is an element susceptible to volatilization losses during heating of the sample, it was chosen to perform the digestion assisted by microwave 


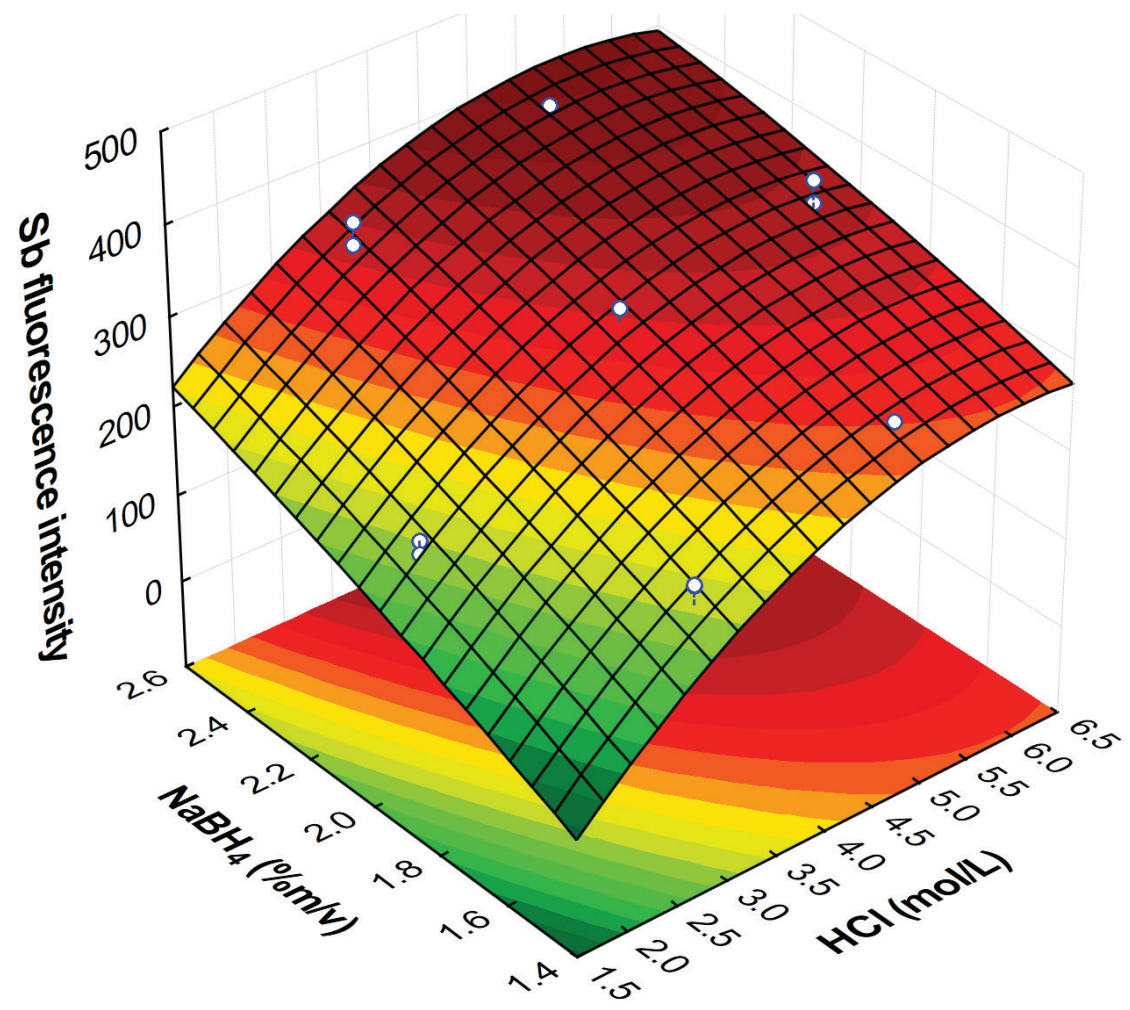

Figure 2 - Response surfaces for quadratic function adjusted to the data obtained from application of the Doehlert design in the optimization of stibnite generation.

energy in a pressured system. To obtain digested samples with good characteristics (low residual carbon content, absence of precipitates and undigested particles) in used PTFE pumps it becomes imperative to use an oxidizing acid such as $\mathrm{HNO}_{3}$. However, the excess of $\mathrm{HNO}_{3}$ in the final digested sample makes the reduction process of $\mathrm{Sb}^{5+}$ to $\mathrm{Sb}^{3+}$ inefficient due to the oxidation of the reducing agents (ascorbic acid and KI). Consequently, it disfavors the formation of stibnite $\left(\mathrm{SbH}_{3}\right)$ affecting the accuracy and sensitivity of the atomic fluorescence's measures. Digestion with dilute acids in pressurized systems has proven highly effective in the treatment of various types of samples due to the formation of free radicals that enhance the performance of organic matter decomposition (Araújo et al. 2002, Castro et al. 2009).
To study the adequate proportions of the digester mixture components $\left(\mathrm{HNO}_{3}, \mathrm{HCl}\right.$ and water), a mixture design with higher constraints was used. The establishment of constraints on the variables is necessary to define the experimental area and avoid adverse proportions that make it difficult to obtain digested samples favorable to hydrides generation (such as using 100\% water or high volumes of $\mathrm{HNO}_{3}$ ). For this study, a mass of approximately $0.1 \mathrm{~g}$ of hair sample and three steps of microwave irradiation for $1 \mathrm{~min}$ intercalated with 1 min intervals without irradiation were used. The constraints and performance in terms of fluorescence intensity are shown in Table III.

To the set of obtained results, a quadratic mathematical function was applied to describe the behavior of the data, obtaining the response surface shown in Figure 3. 


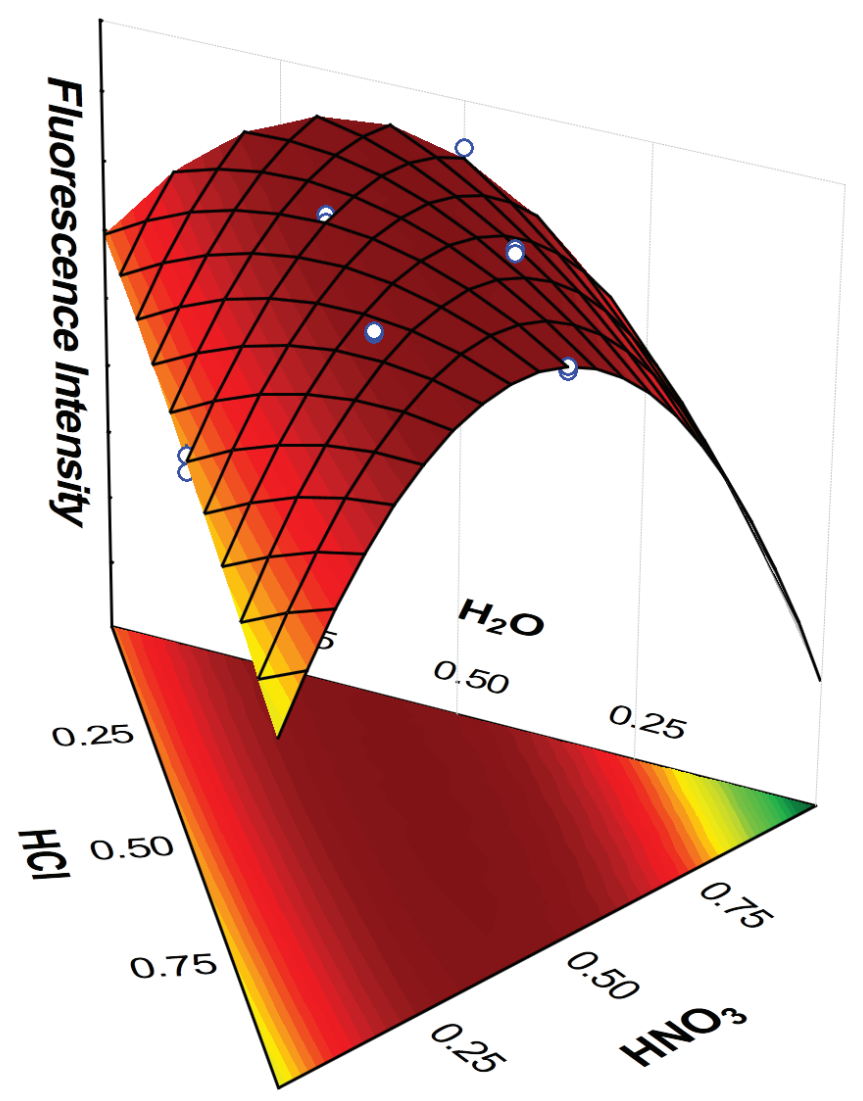

Figure 3 - Response surfaces for quadratic functions adjusted to the antimony fluorescence signal obtained after microwave digestion in pressurized pumps of hair samples.

The highest residual carbon content was found using $50 \% \mathrm{HCl}$ and $50 \%$ deionized water (experiment 3 ) demonstrating the necessity of the existence of any amount of oxidant in the acid digestion process. Lower levels of residual carbon and higher intensities of fluorescence emission were found in experiments that used at least $25 \%$ nitric acid and 50\% water. The proportions tested in experiment $6\left(2.0 \mathrm{~mL}\right.$ of water, $1.0 \mathrm{~mL}$ of $\mathrm{HNO}_{3}$ and $1.0 \mathrm{~mL}$ of $\mathrm{HCl}$ ) were chosen as optimum conditions for microwave digestion.

Analysis of Variance (ANOVA) showed that the quadratic model adjusted to the obtained data using mixtures design does not present significant lack of fit for a confidence level of $96 \%$ (p-value = $0.0435>0.04)$ and that it can be used to describe the behavior of the data within the experimental field studied.

\section{ANALYTICAL CHARACTERISTICS OF THE DEVELOPED METHOD}

Analytical characteristics were accessed to check the suitability of the developed method in the analysis of hair samples and validation of the developed method. The limit of detection (LOD) was calculated by obtaining the standard deviation of the blank signal from ten replicas which was multiplied by a factor of three and a divided by the slope of the analytical curve (Analytical Methods Committee 1987). The limit of quantification (LOQ) was similarly calculated using a factor of ten. In the developed method, the limits of detection and 


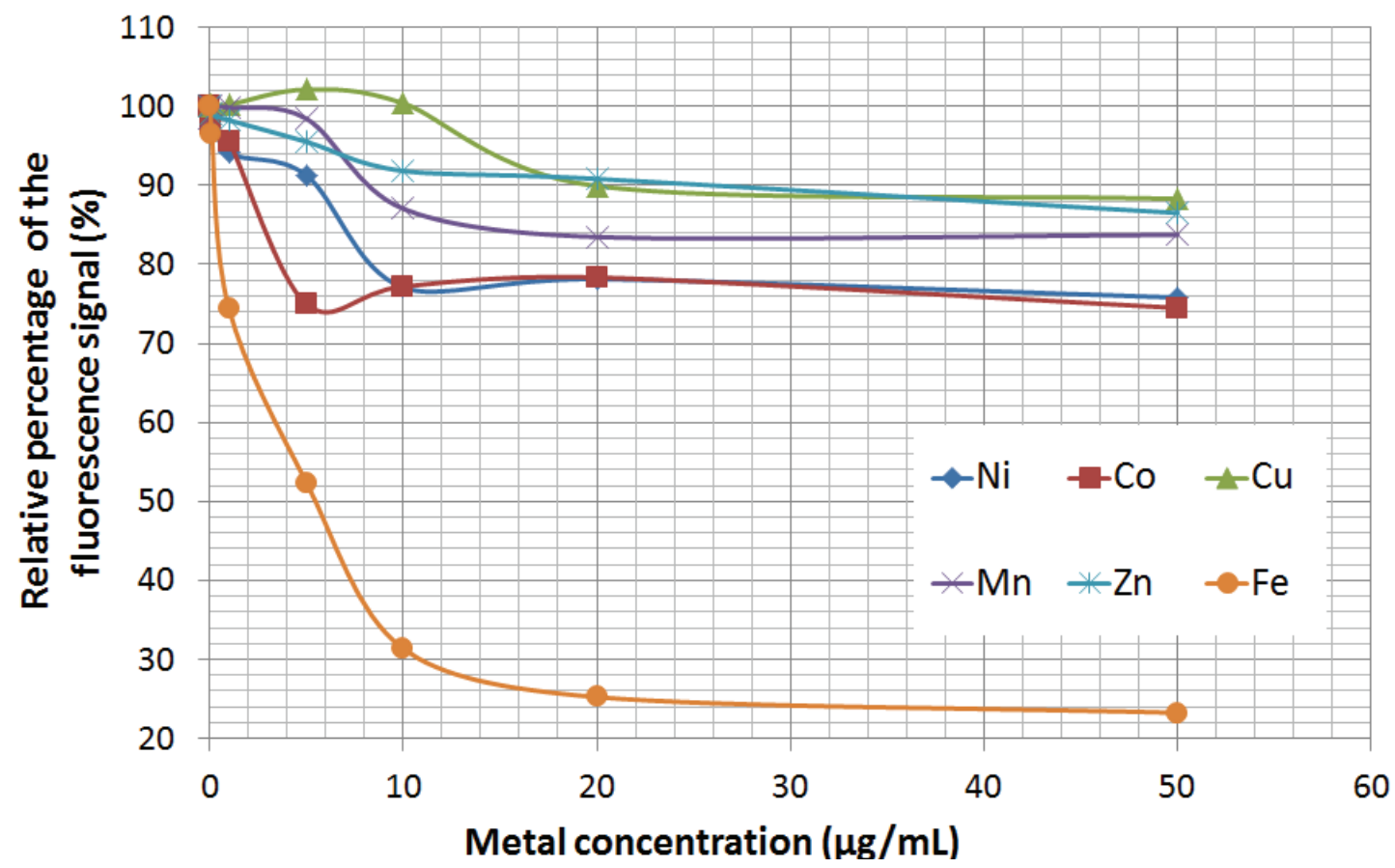

Figure 4 - Studies of the effect of potential interference of $\mathrm{Ni}, \mathrm{Co}, \mathrm{Cu}, \mathrm{Mn}, \mathrm{Zn}$ and $\mathrm{Fe}$ concentrations in the antimony atomic fluorescence signal.

quantification found for the analyzed final solution were 0.28 and $0.96 \mu \mathrm{g} \mathrm{L}^{-1}$ respectively. These limits are correspondent to LOD and LOQ values of 0.57 and $1.92 \mu \mathrm{g} \mathrm{g}^{-1}$ for $0.1 \mathrm{~g}$ of original hair sample taking into account a dilution factor of 20 -fold of obtained digested.

The method precision was accessed on repeatability and expressed as relative standard deviation (\%RSD, $\mathrm{n}=10)$. Using a $10.0 \mu \mathrm{g} \mathrm{\textrm {L } ^ { - 1 }}$ $\mathrm{Sb}$ standard solution, a repeatability of $2.8 \%$ was found.

\section{MATRIX EFFECT STUDIES}

Transition metals can, in the dependence of concentration, cause interference in the hydride generation due the parallel reactions that consume the reducing reagent and, consequently, affect the stibnite transport to the atomizer. With the objective of studying the effect of potential interfering ions $\left(\mathrm{Ni}^{2+}, \mathrm{Co}^{2+}, \mathrm{Cu}^{2+}, \mathrm{Mn}^{2+}, \mathrm{Fe}^{3+}\right.$ and $\left.\mathrm{Zn}^{2+}\right)$ in the $\mathrm{SbH}_{3}$ generation, a $20.0 \mu \mathrm{g} \mathrm{L}^{-1} \mathrm{Sb}^{5+}$ solution was submitted to a hydride generation process in the absence and in the presence of different concentrations $(0.1,1.0$, 5.0, 10.0, 20.0 and $\left.50.0 \mu \mathrm{g} \mathrm{mL}^{-1}\right)$ of these metals. A signal was considered free of interference when generated by a $\mathrm{Sb}$ standard solution in the absence of potential interfering metals. To this signal, a value of $100 \%$ was attributed and the signals obtained in the presence of transition metals were calculated proportionally to this value. Figure 4 shows the results of this study. It was considered that a metal ion causes interference from the concentration that decreases $5 \%$ of the fluorescence emission signal in relation to the original signal. Results (Figure 4) indicate that $\mathrm{Cu}$ is, among the studied metal ions, the one that less causes interferences. Its signal interference begins from a concentration of $10 \mu \mathrm{g}$ $\mathrm{mL}^{-1}$. From this concentration occurs a marked decrease to the Sb signal. Nickel and Co cause interferences from $1.0 \mu \mathrm{g} \mathrm{mL}^{-1}$, Mn and $\mathrm{Zn}$ from 
TABLE IV

Concentration of potentially interfering metal ions in hair sample composed by material from several donors.

\begin{tabular}{ccc}
\hline $\begin{array}{c}\text { Metal } \\
\text { ion }\end{array}$ & $\begin{array}{c}\text { Concentration } \\
\text { in the sample } \\
\left(\boldsymbol{\mu \mathrm { g } \mathrm { g } ^ { - 1 } )}\right.\end{array}$ & $\begin{array}{c}\text { Concentration in the } \\
\text { solution submitted to } \\
\text { hydride generation }(\boldsymbol{\mu g} \\
\left.\mathbf{m L} \mathbf{L}^{-1}\right)\end{array}$ \\
\hline $\mathrm{Ni}^{2+}$ & 1.92 & $9.60 \times 10^{-4}$ \\
\hline $\mathrm{Co}^{2+}$ & $<\mathrm{LQ}$ & $<\mathrm{LQ}$ \\
\hline $\mathrm{Cu}^{2+}$ & 14.7 & $7.35 \times 10^{-3}$ \\
\hline $\mathrm{Mn}^{2+}$ & 2.68 & $1.34 \times 10^{-3}$ \\
\hline $\mathrm{Zn}^{2+}$ & 39.93 & $2.00 \times 10^{-2}$ \\
\hline $\mathrm{Fe}^{3+}$ & 4.96 & $2.48 \times 10^{-3}$ \\
\hline
\end{tabular}

TABLE V

Equations of the analytical curves based

on external standardization and standard addition to the sample techniques.

\begin{tabular}{cccc}
\hline Technique & Equation & $\begin{array}{c}\text { Confidence } \\
\text { interval of } \\
\text { slope* }\end{array}$ & $\mathbf{R}^{2}$ \\
& & & \\
\hline $\begin{array}{c}\text { External } \\
\text { standardi- } \\
\text { zation }\end{array}$ & $\mathrm{y}=26.89 \mathrm{x}+14.19$ & $\begin{array}{c}25.94 \text { to } \\
27.84\end{array}$ & 0.9991 \\
\hline $\begin{array}{c}\text { Standard } \\
\text { addition }\end{array}$ & $\mathrm{y}=27.21 \mathrm{x}+95.14$ & $\begin{array}{c}26.50 \text { to } \\
27.93\end{array}$ & 0.9990 \\
\hline
\end{tabular}

*Confidence level of $95 \%$.

$5.0 \mu \mathrm{g} \mathrm{mL}^{-1}$ and $\mathrm{Fe}$ is the metal ion that causes more interference: from $0.1 \mu \mathrm{g} \mathrm{mL}^{-1}$.

To evaluate the possibilities of interference by these metals in this type of matrix, a sample constituted of the mixture of hair from various donors was analyzed using flame atomic absorption spectrometry (FAAS). The results are shown in Table IV. Since in the proposed method, sample solution must be diluted twenty times, it can be seen that the levels of the naturally occurring elements in this matrix will not interfere in the generation of antimony hydride and dot no demand the use of a masking agent.

The matrix effect and its influence on the analytical curves were also investigated. Standard solutions were prepared using conventional calibration techniques (external standard) and the technique of standard addition of the analyte to the sample solution was also carried out for comparison. The equations of these analytical curves are shown in Table V. As it can be seen, the slopes of the curves obtained by the two methods have high similarity, with a confidence level of $95 \%$. This means that there is no matrix effect and that the two calibration techniques can be used safely. Because of the simplicity and convenience of procedure, the determination of $\mathrm{Sb}$ is recommended using the calibration curve by external standardization.

ACCURACY EVALUATION AND METHOD APPLICATION

After defining the optimal conditions for the antimony determination in hair samples, the method was applied to the analysis of ten samples of hair collected from patients who underwent drug therapy for treatment of Leishmaniasis based on antimonial drugs. Additionally, the method was applied to the analysis of three samples of hair collected from people who did not undergo treatment. It was noted that only the samples of donors subjected to chemotherapy allowed the detection of antimony. The concentrations of $\mathrm{Sb}$ in these samples ranged from 5.29 to $48.9 \mathrm{mg} \mathrm{g}^{-1}$ (Table VI).

Spike tests were performed on three samples to evaluate the accuracy of the method. Thus, $\mathrm{Sb}$ standard solution was added to the sample before the digestion process to better evaluate the possibility of analyte losses. The recoveries were found between 92.2 and $110.0 \%$ and are considered satisfactory for elements in trace amounts, indicating that the developed method has adequate accuracy.

\section{CONCLUSIONS}

The developed method has shown sensitivity, precision and accuracy suitable for the determination of total antimony in hair samples from donors undergoing chemotherapy against 
TABLE VI

Results of the Sb determination, using the analytical method developed, in hair samples from patients undergoing treatment against Leishmaniasis.

\begin{tabular}{ccccc}
\hline $\begin{array}{c}\text { Sam- } \\
\text { ple }\end{array}$ & $\begin{array}{c}\text { Treatment } \\
\text { with } \\
\text { antimonial } \\
\text { drugs? }\end{array}$ & $\begin{array}{c}\text { Added } \\
\text { Sb } \\
\left(\mu \mathbf{g ~ g}^{-1}\right)\end{array}$ & $\begin{array}{c}\text { Found Sb } \\
\left(\boldsymbol{\mu g ~ \mathbf { g } ^ { - 1 } )}\right.\end{array}$ & $\begin{array}{c}\text { Recovery } \\
(\mathbf{\%})\end{array}$ \\
\hline 1 & Yes & 0 & $11.98 \pm 1.27$ & - \\
\hline 2 & Yes & 0 & $12.04 \pm 0.89$ & - \\
\hline 3 & Yes & 0 & $19.79 \pm 1.38$ & - \\
\hline 4 & Yes & 0 & $7.05 \pm 1.57$ & - \\
\hline 5 & Yes & 0 & $36.33 \pm 0.90$ & - \\
\hline & & 50.00 & $91.22 \pm 0.85$ & 110.0 \\
\hline 6 & Yes & 0 & $48.90 \pm 2.92$ & - \\
\hline 7 & Yes & 0 & $5.29 \pm 0.77$ & - \\
\hline 8 & Yes & 0 & $18.18 \pm 1.14$ & - \\
\hline & & 50.00 & $62.88 \pm 0.50$ & 92.2 \\
\hline 9 & Yes & 0 & $19.68 \pm 2.64$ & - \\
\hline 10 & Yes & 0 & $26.19 \pm 0.21$ & - \\
\hline 11 & No & 0 & $<$ LOQ & - \\
\hline 12 & No & 0 & $<$ LOQ & - \\
\hline 13 & No & 0 & $<$ LOQ & - \\
\hline
\end{tabular}

Leishmaniasis based on antimonial drugs. The concentrations of potentially interfering metals naturally present in the capillary matrix on the generation of stibnite do not affect the results obtained by the developed method. The application of multivariate experimental design allowed to find the best proportions of digester agents and the best conditions for generation of stibnite ensuring good performance of the method in the analysis of the studied matrices. The content of antimony in samples from donors not subjected to treatment with antimonial drugs were below the detection limit of the method, while the total antimony concentration in samples from donors undergoing treatment ranged from 5.29 to $48.90 \mathrm{mg} \mathrm{g}^{-1}$. The study allowed the validation of a hydride generation atomic fluorescence spectrometry method in the quantification of antimony in hair, which will enable health professionals to access a new analytical method with sufficient sensitivity and accuracy for information and possibly relate those with health parameters of the individuals.

\section{ACKNOWLEDGMENTS}

The authors greatly acknowledge the financial support provided by Fundação de Amparo à Pesquisa do Estado da Bahia (FAPESB), Conselho Nacional de Desenvolvimento Científico e Tecnológico (CNPq) and Financiadora de Estudos e Projetos (FINEP).

\section{REFERENCES}

ANALYTICAL METHODS COMMitTEE. 1987. Recommendations for the definition, estimation and use of detection limit. Analyst 112: 199-204.

ARAÚJO GCL, GONZALEZ MH, FERREIRA AG, NOGUEIRA ARA AND NÓBREGA JA. 2002. Effect of acid concentration on closed-vessel microwave-assisted digestion of plant materials. Spectrochim Acta B 57: 21212132.

BEZERRA MA, CASTRO JT, MACEDO RCAND SILVADG. 2010. Use of constrained mixture design for optimization of method for determination of zinc and manganese in tea leaves employing slurry sampling. Anal Chim Acta 670: 33-38.

BORELLA P, ROVESTI S, CASELGRANDI E AND BARGELLINI A. 1996. Quality control in hair analysis: A systematic study on washing procedures for trace element determinations. Mikrochim Acta 123: 271-280.

BRASIL. 2007. Ministério da Saúde. Secretaria de Vigilância em Saúde. Manual de Vigilância da Leishmaniose Tegumentar Americana. 2a ed., Brasília - DF : Editora do Ministério da Saúde, 184 p.

BRASIL. 2012. Conselho Nacional de Saúde. Diretrizes e Normas de Pesquisa em Seres Humanos. Resolução 466/12, de 12/12/12.

CASTRO JT, SANTOS EC, SANTOS WPC, COSTA LM, KORN M, NÓBREGA JÁ AND KORN MG. 2009. A critical evaluation of digestion procedures for coffee samples using diluted nitric acid in closed vessels for inductively coupled plasma optical emission spectrometry. Talanta 78: 1378-1382.

CHEVALLIER E, CHEKRI R, ZINCK J, GUÉRIN T AND NOËL L. 2015. Simultaneous determination of 31 elements in foodstuffs by ICP-MS after closed-vessel 
microwave digestion: Method validation based on the accuracy profile. J Food Comp Anal 41: 35-41.

FERREIRA SLC, SANTOS WNL, SANTOS IF, JUNIOR MMS, SILVA LOB, BARBOSA UA, SANTANA FA AND QUEIROZ AFS. 2014. Strategies of sample preparation for speciation analysis of inorganic antimony using hydride generation atomic spectrometry. Microchem J 114: 22-31.

FORTE G, ALIMONTI A, VIOLANTE N, GREGORIO M, SENOFONTE O, PETRUCCI F, SANCESARIO G AND BOCCA B. 2005. Calcium, copper, iron, magnesium, silicon and zinc content of hair in Parkinson's disease. J Trace Elem Med Bio 19: 195-201.

FOUCE RB, REGUERA RM, CUBRÍA JC AND ORDONEZ D. 1998. The pharmacology of leishmaniasis. Gen Pharmac 30: 435-443.

FU Z, WU F, MO C, LIU B, ZHU J, DENG Q, LIAO H AND ZHANG Y. 2011. Bioaccumulation of antimony, arsenic, and mercury in the vicinities of a large antimony mine, China. Microchem J 97: 12-19.

FU J, ZHANG X, QIAN S AND ZHANG L. 2012. Preconcentration and speciation of ultra-trace Se (IV) and Se (VI) in environmental water samples with nano-sized $\mathrm{TiO}_{2}$ colloid and determination by HG-AFS. Talanta 94: 167-171.

GARCÍA JB, KRACHLER M, CHEN B AND SHOTYK W. 2005. Improved determination of selenium in plant and peat samples usin hydride generation-atomic fluorescence spectrometry (HG-AFS). Anal Chim Acta 534: 255-261.

GONZÁLVEZ A, LLORENS A, CERVERA ML, ARMENTA S AND GUARDIA M. 2009. Non-chromatographic speciation of inorganic arsenic in mushrooms by hydride generation atomic fluorescence spectrometry. Food Chem 115: 360-364.

GREGORI I, QUIROZ W, PINOCHET H, PANNIER F AND GAUTIER-POTIN M. 2007. Speciation analysis of antimony in marine biota by HPLC-(UV)-HG-AFS: Extraction procedures and stability of antimony species. Talanta 73: 458-465.

HAGE DS AND CARR JD. 2012. Química analítica e análise quantitativa. $1^{\mathrm{a}}$ ed., São Paulo: Pearson Prentice Hall, 708 p.

KRACHLER M, SHOTYK W AND EMONS H. 2001. Digestion procedures for the determination of antimony and arsenic in small amounts of peat samples by hydride generation atomic absorption spectrometry. Anal Chim Acta 432: 307-314.

LIU B, WU F, LI X, FU Z, DENG Q, MO C, ZHU J, ZHU Y AND LIAO H. 2011 Arsenic, antimony and bismuth in human hair from potentially exposed individuals in the vicinity of antimony mines in Southwest China. Microchem J 97: 20-24.

MATOS-REYESA MN, CERVERA ML, CAMPOS RC AND GUARDIA M. 2010. Total content of As, Sb, Se, Te and Bi in Spanish vegetables, cereals and pulses and estimation of the contribution of these foods to the Mediterranean daily intake of trace elements. Food Chem 122: 188-194

MENDIL D, BARDAK H, TUZEN M AND SOYLAK M. 2013. Selective speciation of inorganic antimony on tetraethylenepentamine bonded silica gel column and its determination by graphite furnace atomic absorption spectrometry. Talanta 107: 162-166.

MIRAVET R, LÓPEZ-SÁNCHEZ J AND RUBIO R. 2006. Leachability and analytical speciation of antimony in coal fly ash. Anal Chim Acta 576: 200-206.

MONTESINOS PC, CERVERA ML, PASTOR A AND GUARDIA M. 2004. Determination of As, Sb, Se, Te and $\mathrm{Bi}$ in milk by slurry sampling hydride generation atomic fluorescence spectrometry. Talanta 62: 175-184.

RAHMAN L, CORNS WT, BRYCE DW AND STOCKWELL PB. 2000. Determination of mercury, selenium, bismuth, arsenic and antimony in human hair by microwave digestion atomic fluorescence spectrometry. Talanta 52 : 833-843.

REYES MNM, CERVERA ML, CAMPOS RC AND GUARDIA M. 2008. Non-chromatographic speciation of toxic arsenic in vegetables by hydride generation-atomic fluorescence spectrometry after ultrasound-assisted extraction. Talanta 75: 811-816.

SANTOS WNL, CAVALCANTE DD, MACEDO SM, NOGUEIRA JS AND SILVA EGP. 2013. Slurry sampling and HG AFS for the determination of total arsenic in rice samples. Food Anal Method 6: 1128-1132.

SEZGIN HV, GÖKÇEL HI AND DILGIN Y. 2015. Adsorptive anodic stripping voltammetric determination of antimony (III) on a glassy carbon electrode using rivastigmine as a new chemical receptor. Sensors Actuat B: Chem 209: 686-694.

SHI J, TANG Z, JIN Z, CHI Q, HE B AND JIANG G. 2003. Determination of $A s(I I I)$ and $A s(V)$ in soils using sequential extraction combined with flow injection hydride generation atomic fluorescence detection. Anal Chim Acta 477: 139-147.

SMRKOLJ P, POGRAJC L, HLASTAN-RIB C AND STIBILJ V. 2005. Selenium content in selected Slovenian foodstuffs and estimated daily intakes of selenium. Food Chem 90: 691-697.

VIOLANTE N, SENOFONTE O, MARSILI G, MELI P, SOGGIU ME AND CAROLI S. 2000. Human hair as a maker of pollution by chemical elements emitted by a thermoelectric power plant. Microchem J 67: 397-405.

WU H, WANG X, LIU B, LIU Y, LI S, LU J, TIAN J, ZHAO W AND YANG Z. 2011. Simultaneous speciation of inorganic arsenic and antimony in water samples by hydride generation-double channel atomic fluorescence spectrometry with on-line solid-phase extraction using single-walled carbon nanotubes micro-column. Spectrochim Acta B 66: 74-80. 